\title{
EDUCACIÓN, DIVERSIDAD DE LOS MÁS CAPACES Y ESTEREOTIPOS DE GÉNERO
}

[Education, diversity of the most able students and gender stereotypes]

Article record
$\underline{\text { About authors }}$
$\underline{\text { HTML format }}$

Abstract
This work analyses data from two consecutive studies car-
ried on the same sample during the academic courses:
$2000-01$ and 2003-04, and its objective is to know the per-
ceptions, beliefs, attitudes and values of this sample about
the situation of the more able students from the gender's
perspective. The sample was chosen through the criterion
of being students that have earned the Baccalaureate Ex-
traordinary Award. These valuations were gathered by
means of free discussion in small groups. In the first study
we also gathered their parents' opinions, together with the
ones from a group of their baccalaureate teachers. The
main conclusion drawn is that school does not attend to
these kinds of students, but on the contrary, it keeps on
repeating and repeating, and despite of the advance to-
wards the equality of gender, stereotypes and prejudices
that double discriminates most capable women still pre-
vail. The advancement has been greater among the
younger and more cultivated population as well as in the
most educated and open contexts like university and cities,
but even in in this population and under the "politically
correct”, we still find buried redoubts of machismo.

\section{Keywords}

Attention to the diversity; education, high ability and gender; students' stereotypes and attitudes, parents and teachers and gender; education and equality and gender; gender stereotypes in the more able students.
Carmen Jiménez (mjimenez@edu.uned.es)

Beatriz Álvarez (balvarez@edu.uned.es)

Juan Antonio Gil (jgil@edu.uned.es)

María de los Ángeles Murga (mmurga@edu.uned.es)

José Antonio Téllez (jatellez@edu.uned.es)
Ficha del artículo

$\underline{\text { Sobre los autores }}$

Formato HTML

\section{Resumen}

La colaboración analiza datos de dos estudios consecutivos sobre la misma muestra realizados durante los cursos 2000-01 y 2003-04, y su objetivo es conocer las percepciones, actitudes y valores de dicha muestra sobre la situación de los alumnos y alumnas más capaces desde la perspectiva del género. La muestra ha sido elegida por haber obtenido Premio Extraordinario de Bachillerato, y se han recogido dichas valoraciones mediante la discusión libre en pequeños grupos. En el primer estudio se han recogido también las opiniones de sus padres y las de un grupo de sus profesores de bachillerato. Se concluye que la escuela no atiende a estos alumnos sino que se limita a repetir, repetir y repetir, y que pese al avance producido hacia la igualdad de los géneros, perviven estereotipos, prejuicios y actitudes que discriminan doblemente a la mujer capaz. El avance ha sido mayor entre la población más joven y más ilustrada y en los ámbitos más cultos y abiertos como la universidad y las ciudades, pero aún en ellos, persisten reductos machistas soterrados bajo lo "políticamente correcto”.

\section{Descriptores}

Atención a la diversidad; educación, alta capacidad y género; estereotipos y actitudes de alumnos, padres y profesores y género; educación e igualdad y género; estereotipos de género en los alumnos más capaces. 


\section{INTRODUCCIÓN}

La presente colaboración analiza datos de dos estudios consecutivos realizados sobre los mismos alumnos en el marco de una línea de investigación sobre Educación, alta capacidad y género. Su objetivo es conocer las percepciones, creencias, actitudes y valores de una muestra de alumnos con rendimiento excelente, sobre la situación de los alumnos y alumnas más capaces dentro de la escuela, haciendo especial incidencia en la perspectiva del género. La muestra ha sido elegida por haber obtenido Premio Extraordinario de Bachillerato (PEB), y en esta colaboración se analizan las valoraciones de los participantes mediante la discusión libre en pequeños grupos, valoraciones recogidas en los cursos académicos 2000-01 y 2003-04, respectivamente. Además de las opiniones de los alumnos, en el primer estudio se han recogido también las de sus padres y las de un pequeño grupo de sus profesores de bachillerato.

Procederemos del siguiente modo. En primer lugar esbozamos el estado de la cuestión respecto al desarrollo evolutivo y su configuración por género en los grupos con capacidad intelectual; en segundo lugar exponemos la metodología y resultados obtenidos del análisis racional de las respuestas dadas en los grupos de discusión, terminando con la discusión y conclusiones que de ellas emergen. La hipótesis de partida es que la escuela apenas si atiende la diversidad de los más capaces y que dentro y fuera de sus muros la igualdad y equidad entre los géneros sigue siendo una utopía pese al avance general producido, hipótesis que se confirma.

\section{ESTADO DE LA CUESTIÓN}

Atención a la diversidad, necesidades educativas especiales, escuela y sociedad inclusivas, equidad y excelencia en educación, el dilema y desafío de la diferencia y terminologías afines, forman parte del universo intelectual de las últimas décadas, y cobran im- portancia cuando se toma conciencia de que la diversidad es una característica definitoria de las sociedades contemporáneas, y que es de importancia radical el estudio sobre sus orígenes, su modelado social y sus consecuencias (Henin-Stout y Brown-Cheatham, 1999). Nacemos diferentes y nos hacemos y nos hacen ser diferentes.

En las ciencias sociales, la diferencia se ha percibido como problemática, déficit o desventaja y se ha actuado con políticas compensatorias $\mathrm{y}$ adaptativas tomando como norma al grupo social dominante, o los varones de la clase media en sentido amplio, pues vivimos en una sociedad y cultura patriarcal (Kincheloe y Steinberg, 1999). Sin embargo, hay que pasar a percibir la diferencia de género, de capacidad, de cultura, de etnia, como lo natural en el hombre, en sus grupos y en la evolución humana; tomar conciencia de que son variaciones naturales poco comunes, habituales o frecuentes, y superar un pasado de exclusión que ha negado y niega la diferencia, como si la naturaleza creara aberraciones cada vez que un individuo diferente aparece en el horizonte social (Tistone, Floria y Rose, 2003). La variabilidad es propia de la especie y su carácter genético es conformado y reinterpretado desde la construcción social (Sleeter, 2003). El nuevo referente es que la diversidad humana enriquece y requiere una educación de calidad similar para todos (Jiménez Fernández, 2004).

\subsection{Educación, alta capacidad y género}

En las últimas décadas en los países desarrollados ha tenido lugar un importante avance hacia la igualdad de los géneros en los ámbitos educativos y sociales, pero aún queda camino por recorrer. La interpretación dada a las diferencias de género y de capacidad es esencial para decidir sobre los modelos de intervención educativa y social. La revisión de estudios sobre los superdotados pone en evidencia el papel determinante de la educación en la realización de la capacidad. Y viceversa. La ausencia de oportunidades y desafíos educativos adecuados, lleva 
al encubrimiento de la capacidad que no se desarrolla aunque se posea (Kerr, 1991).

Los estudios sobre los chicos y chicas más capaces muestran algunas diferencias, que parecen estar en plena ebullición. Las mujeres evidencian más precozmente la capacidad; desarrollan intereses mixtos o masculinos y femeninos; hasta la adolescencia destacan en capacidad verbal; obtienen rendimientos escolares similares o algo superiores a los de los varones; muestran (¿mostraban?) escaso interés en participar en programas específicos para los más capaces por temor a ser socialmente rechazadas y son menos elegidas para participar en ellos (Daignault, Cheryl Pohman y McCabe, 1999); elijen estudios de todo tipo, aunque predominen discretamente las Humanidades y Ciencias Sociales. En la adolescencia sufren el dilema feminidad-capacidad, atenuado en los contextos donde ha avanzado la visibilidad social y profesional de la mujer (Kerr, 2000), y padecen síndromes como miedo al número y miedo al éxito o temor a sobresalir en campos tradicionalmente reservados al varón (Noble, 1987; Landau, 2003). El síndrome del impostor es frecuente en las mujeres profesionales que alcanzan éxitos elevados en campos tradicionalmente masculinos, y se refleja en la aparición de un sentimiento de autoestima extremadamente bajo que lleva a la mujer de éxito a minusvalorar sus merecidos logros atribuyéndolos a terceros, y a culpabilizarse de los problemas que puedan acaecer en su vida privada (Clance, 1985).

El desarrollo evolutivo de los varones capaces sigue, al alza, el patrón convencional masculino. Destacan en capacidad matemática y espacial, en intereses científicos, les gusta participar en programas adecuados a su capacidad, y optan mayoritariamente por estudios científicos y técnicos. Por otra parte, los padres esperan de ellos realizaciones acordes con el estereotipo del hombre capaz, equivalente a estudios con prestigio social y reconocimiento económico, y tempranamente les orientan en dicha dirección y les disua- den sutil y persistentemente de elecciones poco seguras. Con las hijas, el principal objetivo paterno es proteger su futuro de mujer desvalida $\mathrm{y}$, en consecuencia, apoyan su educación pero aceptan en ellas opciones académicas y profesionales de alto, medio y bajo nivel, aunque las madres parecen impulsar silenciosamente las altas aspiraciones de las hijas capaces, tanto las madres profesionales como aquellas que viven la madurez desde el silencio y la desvalorización públicas impuestos al trabajo femenino en la vida privada (Jiménez, Aguado, Álvarez, Gil y Jiménez, 2002; Jiménez, Álvarez, Gil, Murga y Téllez, 2005; Kerr, 2000).

El rendimiento escolar femenino evoluciona positivamente en todos los niveles del sistema educativo, tendiendo a superar al varón. En el caso español, desde comienzos de siglo la matrícula en la universidad tiene mayoría femenina en los estudios de Humanidades, Ciencias Sociales, Ciencias de la Salud y Ciencias Experimentales, en el último caso con alguna excepción como físicas (CIDE/Instituto de la Mujer, 2001). Su avance ha sido menor en los estudios técnicos, aunque aumenta su presencia sin prisa pero sin pausa. Representan aproximadamente el 30 por ciento de la matrícula en las universidades politécnicas con variaciones que oscilan entre el 40 por ciento en arquitectura y en torno al 8 por ciento en ingeniería civil, fenómeno similar al ocurrido en países como Estados Unidos (Lubinski, Benbow y Morelock, 2000). Cuanto más elevado es el nivel educativo, caso del doctorado, o más larga es la carrera, caso de las licenciaturas de doble ciclo, mayor es el número de mujeres, mujeres que repiten menos curso que los hombres (CIDE/Instituto de la Mujer, 2001; Jiménez Fernández, 2004).

En nuestro país el 67 por ciento de los jueces son mujeres y se constata que en el acceso a la función pública de alto nivel, la mujer encuentra uno de los terrenos más equitativos para competir con el varón en función de la capacidad y el mérito respectivo; fuera de 
la Administración no encuentran fácilmente la equidad debida (Martín Serrano, 2004). En el ámbito de la universidad sólo el 13 por ciento de los cátedras están ocupadas por mujeres, mujeres que han de mostrar con nitidez su valía y revalidarla día a día (García de Cortazar y García de León, 1997). Como señalan algunos titulares periodísticos "las mujeres no encuentran sitio en la primera fila universitaria”, o lo encuentran con mayor dificultad que los varones. Esta última situación afecta al conjunto de los países desarrollados y ha llevado a la Función Pública Francesa a elaborar un interesante dossier sobre la paridad de género (Service $\mathrm{Pu}$ blic, 2005), pues en Francia, desde hace una larga década hay más mujeres que hombres en la Administración pero como en España, están infrarrepresentadas en la función pública directiva.

Otras profesionales con prestigio como las ingenieras, encuentran algunas dificultades específicas debido a su condición de féminas. Un estudio sobre 56 ingenieras (López Sáez, 2003) señala, entre otros, que durante los estudios se han sentido presionadas para rendir, pues no se acepta igual que una chica pueda tardar siete o más años en una carrera de seis que cuando es varón el estudiante; en el primer caso el comentario es "que hubiera elegido una carrera más fácil”, comentario que en el caso del chico toma el formato de "pobrecito, ha elegido una carrera muy dura". Durante la carrera tienen pocos referentes femeninos y creen que los demás las perciben como menos femeninas que la población general, extremo que rechazan. De hecho, el 93 por ciento de las casadas se ha casado con otro ingeniero, endogamia que podría tener una explicación parcial en el prolongado tiempo de convivencia, y a que entre ellos se perciben mutuamente como los iguales que realmente son. En otros contextos aún bastante amplios, la broma fácil amenaza al varón que se casa con una mujer estereotipadamente definida como poco femenina y que profesionalmente puede valer y destacar tanto o más que el varón. Que destaque el varón es la norma, lo correcto; que destaque la mujer es la excepción que se admite en determinadas circunstancias o significa el castigo social para el varón y para la mujer, desde prismas diferenciados.

Las ingenieras aparecen como mujeres asertivas, luchadoras, que aman su trabajo y disfrutan haciéndolo bien, conscientes de que valen igual que sus compañeros, consciencia que adquieren tempranamente pues están acostumbradas a trabajar duro y con éxito y a despertar cierta admiración social por la opción elegida. Son moderadamente críticas con las discriminaciones que sufren las mujeres y no quieren trato de privilegio sino ser una profesional más que como tal debe ver reconocido y apoyado su trabajo. Son conscientes de que primero tienen que demostrar que valen, para seguir demostrando que valen y hacen tanto como sus compañeros, con cuyas relaciones profesionales disfrutan. $\mathrm{Al}$ ser minoría, mujeres y en un ámbito masculinizado, están prácticamente fuera de las líneas de promoción y de los puestos de alta dirección. De hecho, los compañeros las excluyen de los circuitos informales donde se cuecen los posibles ascensos, y son objeto de las iras varoniles si estos intuyen que la empresa cuenta con ellas para un puesto de rango superior.

\subsection{Educación, género y característi- cas de personalidad}

No resulta fácil percibir las desiguales condiciones existentes para el logro y reconocimiento del rendimiento excelente en cada uno de los géneros. Acostumbrados a concebir y percibir el mundo desde la perspectiva pública del varón, el mundo que existe más allá y más acá de dicha perspectiva es como si no existiera y careciera de valor. Y no es así (Kincheloe y Steinberg, 1999). Existe otro mundo, el femenino, en buena parte construido socialmente como el masculino, y que es igualmente importante para el ser y el estar de la especie humana, mundo que requiere una revalorización social que reequilibre su intrínseco valor. 
Los asuntos y cambios complejos llevan su tiempo aunque no siempre se arreglan con el tiempo. En España hasta hace un siglo las chicas necesitaban un permiso especial para poder cursar los estudios de bachillerato, requisito imprescindible para ingresar en la Universidad cuyo acceso general estuvo vetado a la mujer hasta 1910, año en que se promulgaría la igualdad de derechos de ambos géneros en el acceso a todos los estudios. Pero el reconocimiento legal no significó igualdad real. Sin necesidad de documentar los prejuicios, sesgos y desigualdades existentes, podemos señalar que un importante grupo de los profesionales que seguimos en activo hemos conocido en carne propia cómo se diferenciaba la educación de chicos y chicas en la enseñanza primaria, en el bachillerato y en las Escuelas Normales de Maestros. En éstas se suprimían de los exámenes de las chicas las materias científicas; en la enseñanza primaria y en bachillerato el currículo femenino se diferenciaba en la misma línea y existían tempranamente materias típicamente femeninas como labores y hogar (Flecha, 1996).

Más allá del derribo de las barreras legales, interesa constatar como pervive el reconocimiento discriminado de la singularidad de cada género, entre otras razones por el peso de las tradiciones, instituciones, sesgos y estereotipos existentes, peso y sesgos que no se hacen evidentes de forma rápida y lineal, y cuando se vuelven evidentes, tardan en ser corregidos.

Como recogemos en otro trabajo (Jiménez Fernández, 2004), de un conjunto de estudios se desprende que a pesar de su capacidad objetiva, las chicas dotadas tienden a tener menor confianza en sí mismas y minusvaloran sus logros más que los chicos. Por ejemplo, no dan importancia mayor a aprobar bien los cursos, a ser admitidas en determinado tipo de estudios o a conseguir una beca o premio. En los estudios diferenciales clásicos las mujeres son descritas como más dependiente, con menor autoconcepto y con un control más externo que los varones, características que aparecen también entre las más capaces cuando se comparan con sus iguales del otro género.

Jones y Smark (1995) señalan que en Reino Unido y a la edad de 16 años, la participación de chicas y chicos en programas de matemáticas era llamativamente desproporcionada. Sin embargo, ha habido un reajuste en la interpretación de este dato. Hace unos años ese decía que las chicas estaban fracasando en las matemáticas cuando la realidad era que no las elegían; a finales de los noventa se ha pasado a señalar que las chicas están eligiendo fuera de las matemáticas porque son campos que les atraen más (Lubinski, Benbow y Sander, 1993; Lubinski, Benbow y Morelock, 2000), aunque paso a paso van avanzando en los diferentes tipos de estudios. El avance parece haber ido desde los estudios tradicionalmente femeninos 0 humanidades, a los más novedosos y menos marcados por ello por el estereotipo del género como económicas y empresariales, para llegar finalmente a los típicamente masculinos o ciencias y estudios técnicos.

Esta interpretación más ajustada apunta a los intereses y valores. Jones y Smark se centran en las actitudes y revisan varias investigaciones para concluir que la confianza es un factor clave que subyace a esta diferencia entre los géneros. Que se trata de una conducta compleja, una actitud que puede y debe ser modificada. Las chicas como grupo se muestran más inseguras, con más pobre autoconcepto, lo que exige una reflexión rigurosa para dar una educación no sexista ni discriminatoria de la capacidad superior. El grupo de las niñas y mujeres con capacidad pagan un alto precio por el hecho de serlo pues, dado el peso de los estereotipos, a menudo se sienten atrapadas entre exigencias contradictorias.

Por ejemplo, el chico inquisitivo, la mente ávida, la argumentación a las explicaciones del profesor, pueden servir para catalogar al 
alumno como precoz y brillante; esa misma conducta en una niña puede resultar molesta y percibirse como agresiva y poco femenina. Los estereotipos penetran los muros sociales de forma sutil o descarada y saltarse ciertas normas del aula como esperar el turno para preguntar o contestar, es una conducta muy probable en los chicos capaces y que se acepta mal en las chicas (Landau, 2003). La falta de confianza, los sentimientos de culpabilidad, pueden tener diversas manifestaciones según el género.

Horner (1972) acuñó el concepto de miedo al éxito, factor que afecta a una parte de las niñas y mujeres brillantes, pues temen ser demasiado competentes en su trabajo y como consecuencia, merecer el rechazo de sus compañeros y no resultar atractivas para sus parejas. Puede llevar a una pérdida de confianza en la propia capacidad, con efectos devastadores si ocurre en los años de las opciones académicas que marcarán el futuro de su trayectoria académica y profesional.

Este tipo de factores pueden ser controlables al estar relacionados con la expectativa de éxito, la confianza en la propia capacidad y el valor incentivo de la tarea, características ligadas al rendimiento de las mujeres brillantes. De hecho, en los ámbitos más evolucionados en donde la visibilidad profesional de la mujer es mayor en los diferentes órdenes de la vida, y donde además se percibe su presencia con relativa normalidad, el miedo al éxito y el temor a las matemáticas desaparece entre las jóvenes, para permanecer activo en los medios más cerrados y menos cultivados (Alfeld y Corine, 1999; Benbow, 1992; Jiménez, Álvarez, Gil, Murga y Téllez, 2005).

Otras características como el perfeccionismo y el síndrome del impostor parecen afectar particularmente a la población femenina más capaz. El perfeccionismo puede definirse como el establecimiento de metas muy altas en los diferentes campos de la vida, lo que a la larga resulta insostenible para cual- quier ser humano. Los chicos capaces tienden a plantearse metas elevadas y exigentes, pero con distinta visión y en campos limitados. En cambio, las chicas brillantes tienen el riesgo de querer ser perfectas en todo lo que hacen e invierten una considerable energía en intentar destacar como estudiante, como amiga, como mujer, como hija, como investigadora, como atleta, en lugar de fijarse objetivos razonables para sí mismas. El sutil sistema de premios y castigos imperante en el entorno, las crisis de confianza que pueden sobrevenirle, la falta de experiencia y la necesidad de responder bien a las demandas, les lleva a esforzarse por tener éxito en niveles cada vez más altos, y cuando los logran, puede sobrevenir el síndrome del impostor (Clance, 1985).

Muchas mujeres capacitadas tienden a considerar la mediocridad en cualquier terreno como un desvalor propio, y el rechazo de una oportunidad como una pérdida de posibilidades, un fracaso en último término. Asimismo experimentan un profundo sentido de inadecuación que suele manifestarse con una mentalidad de "impostora", expresada por una ansiedad permanente de que la propia fachada de la competencia sea descubierta teniendo como resultado la humillación y el fracaso. Reacción al éxito que afecta en menor grado al grupo de los hombres brillantes, que tiende a atribuir sus logros a la capacidad y al esfuerzo y, secundariamente, a factores externos. Se trata de una conducta aprendida, alimentada por los otros significativos en sus vidas, y puede aparecer también entre las mujeres que han sido capaces de abrirse paso en profesiones no excesivamente cualificadas, pero significativas en su medio por ser propias del varón y significar un logro social (Elejabeita Tavera, 2003).

Finalmente señalar que se apunta a que en la adolescencia y juventud la población femenina, debido a su socialización diferencial, tiende a planificar y prever menos su futuro, pues incluso las chicas brillantes podrían adolecer de un visión realista de lo que 
es el futuro de la mujer adulta, de las imposiciones que plantean las realidades económicas, familiares y sociales de la vida, e ignorar el hecho de que un buen número de ellas tendrán que autogobernarse y autofinanciarse o hacer lo propio con otros miembros de su familia. Quizá sea este un terreno en el que el revisionismo es mayor y en el que el peso de los estereotipos y mensajes ambivalentes están en plena ebullición y en plena confusión. El hecho de que siempre haya sido el varón el responsable de la familia, es un dato que sigue vivo en determinados contextos, al tiempo que los importantes cambios ocurridos sobre la igualdad de los sexos da pié a pensar y postular otro tipo de responsabilidad.

Debido a estos y otros factores, muchas chicas crecen confiadas en que llegará alguien que se ocupará de ellas, sin pararse a pensar en las implicaciones profesionales de sus opciones curriculares, por lo que algunos autores denominan esta característica como síndrome de cenicienta. Por su parte, los varones brillantes crecen con mayor conciencia de que tienen que planificar una carrera profesional para toda la vida, y hacen elecciones más sólidas, de mayor alcance y más apropiadas, entre otras razones porque el contexto familiar les impele a ello desde edades tempranas, si bien en el caso de los estudiantes con rendimiento elevado y buena capacidad, los padres apoyarían a la par las altas aspiraciones académicas de hijos e hijas (Jiménez, Álvarez, Aguado, Gil y Jiménez, 2001), y ellas mismas parecen haber desarrollado una clara conciencia de la propia autonomía personal y señalan que es discriminación no ser igualmente exigentes con el rendimiento y las opciones curriculares de hijos e hijas, extremo este en el que coinciden los varones (Jiménez, Álvarez, Gil, Murga y Téllez, 2004, 2005).

Esta falta de planificación y realismo tiene que ver asimismo con su visión de los estudios universitarios y postuniversitarios, la profesión, el matrimonio y los hijos. Por ejemplo, algunas chicas con buen rendimiento no ven mayor dificultad para un futuro profesional que sueñan brillante, en la interrupción de los estudios y de la carrera profesional durante unos cuantos años, y en términos crudos no es así. La situación no parece haber mejorado en el siglo XXI, especialmente en el caso de la empresa privada.

Hay una característica que algunos han denominado estilo de vida (Lubinski, Benbow y Sanders, 1993) y que lo destacan respecto de los intereses y valores pues podría ser el pivote sobre el que se organiza la estructura personal, vocacional y social de los géneros. Y lo hacen desde la reconceptualización del programa SMPY (Study of Matematically Precocius Youth) por entender que las elecciones sobre el estilo de vida podrían ser el aspecto más crítico para comprender las diferencias de género, pese a que apenas si están documentadas pues no son típicamente evaluadas en los cuestionarios estandarizados de intereses y valores. Probablemente ejercen un fuerte efecto en las diferencias de género, aún en disciplinas en las cuales chicos y chicas son proporcionalmente comparables en términos de sus expedientes académicos. Se refieren a si proyectan trabajar a tiempo completo cuando sean adultos $y$ a como conceptualizan éticamente el mundo cada uno de los géneros.

En las tres primeras cohortes del SMPY (el programa nació en 1971 y sigue vivo) más del 95 por ciento de los chicos planificaba hacer una carrera superior y dedicarse a su trabajo a tiempo completo, mientras que menos de la cuarta parte de ellos esperaba que hiciera lo mismo su futura esposa, y más de la mitad esperaba que ésta dejase de trabajar cuando tuviera hijos. Por su parte, no todas las chicas con talento matemático planificaban realizar estudios superiores; aproximadamente la mitad de las que pensaban hacerlo esperaban dedicarse a su profesión ininterrumpidamente aunque veían en los hijos un problema, y el 50 por ciento restante se dis- 
tribuía en partes casi iguales entre dedicarse al trabajo a tiempo parcial y abandonar este cuando tuvieran hijos, porcentaje que ha permanecido estable a lo largo de dos décadas. Son las alumnas que piensan dedicarse a tiempo completo a su profesión las más partidarias de la aceleración de los estudios y de cursar una carrera superior (Fox y Zimmerman, 1988; Webb, Lubinski y Benbow, 2003).

Pese a los cambios producidos en los últimos años no hay que hipersimplicar la situación. Si las chicas estudiadas en los años setenta narran frustraciones tempranas a la hora de obtener juguetes de construcción o de química o de explorar el entorno libremente, y al mismo tiempo han experimentado una fuerte ayuda y altas expectativas de sus progenitores, los chicos y chicas actuales encuentran una sociedad más abierta e igualitaria pero también conflictos sin resolver que se han agudizado, aunque se expresen de forma sutil y ambigua. El importante avance de la mujer como trabajadora, el descenso de los índices de natalidad, la resistencia a democratizar los distintos órdenes de la vida y la constatación de que las altas profesionales suelen darse con más frecuencia entre las solteras y las separadas, crean conflictos en los hombres, en las mujeres y en sus entornos y son percibidos por los hijos.

Actualmente la legislación trata de facilitar la conciliación de la vida familiar y profesional en varones y mujeres, y es esta nueva mentalidad la que presenta los alumnos PEB como veremos a continuación. Mentalidad de cambio en determinados aspectos, que se constata asimismo en las opiniones expresadas por varones y mujeres de primero de carrera y con rendimiento excelente (Jiménez, Álvarez, Gil, Murga y Téllez, 2006).

No obstante, no es indistinto que desde los ámbitos más reflexivos en los últimos años se prefiera hablar de estudios sobre el género en lugar de estudios sobre la mujer; de igualdad de hombres y mujeres en lugar de igual- dad de la mujer; de democratización de la vida doméstica y de compromiso y pacto social entre hombre y mujeres en los distintos órdenes de la vida. Un ejemplo vale más que mil palabras, y los chicos y chicas que consideramos perciben con nitidez los dobles lenguajes, las contradicciones y ellos y ellas dudan sobre sus opciones personales más profundas.

En una publicación anterior (Jiménez, Álvarez, Gil, Murga y Téllez, 2005) exponemos la situación y evolución de la muestra que ahora consideramos en las dimensiones intelectiva, aptitudinal y de personalidad desde la perspectiva del género, medidas estas dimensiones a través de tests tipificados y de cuestionrios ad hoc. Simplemente apuntar que el único ámbito donde existen algunas diferencias significativas, es precisamente en el mundo de los intereses, valores y prioridades; por lo demás, chicos y chicas aparecen como personas seguras, asertivas, con ambición y expectativas, comprometidas con su tiempo y con un discurso de igualdad y equidad entre los géneros, que encierra avances y contradicciones, como esperamos mostrar.

\section{MÉTODO}

Pasamos a presentar el análisis de las respuestas dadas por alumnos, padres y profesores a los temas planteados en los grupos de discusión en el primer estudio, y que giran en torno a cómo se contemplan los alumnos más capaces desde el sistema educativo y a cómo perciben la igualdad de los géneros en distintos ámbitos vitales. Los datos del segundo estudio se refieren sólo a los alumnos y a sus opiniones y valoraciones de la igualdad y la equidad entre los géneros en los diversos órdenes de la vida.

\subsection{Población y muestra}

Queremos destacar de entrada que se trata de una población singular o la de los alumnos que han obtenido Premio Extraordinario de Bachillerato (PEB) en la Comunidad de 
Madrid. La obtención del PEB está regulada y para aspirar al mismo es requisito haber obtenido una media de sobresaliente en los estudios de bachillerato. Los aspirantes deben superar una prueba compleja compuesta de varias partes y los que finalmente lo ob- tienen, pueden aspirar a Premio Nacional de Bachillerato. Se puede otorgar un PEB por cada mil alumnos matriculados en el último curso de bachillerato objeto de dicho premio. El contenido de la tabla 1 muestra lo selectiva que resulta ser la población PEB.

Tabla 1. Aspirantes, alumnos presentados y alumnos premiados o población PEB

\begin{tabular}{|c|c|c|c|c|}
\hline & $\begin{array}{c}\text { POBLACIÓN DE } \\
\text { SEGUNDO DE } \\
\text { BACHILLERATO }\end{array}$ & $\begin{array}{c}\text { ASPIRANTES } \\
\text { A PEB }\end{array}$ & $\begin{array}{c}\text { PRESENTADOS } \\
\text { A PEB }\end{array}$ & $\begin{array}{c}\text { PREMIADOS/ } \\
\text { POBLACIÓN } \\
\text { PEB }\end{array}$ \\
\hline CURSO 2001 / 2002 & 47.546 & 728 & 246 & 36 \\
\hline CURSO 2002 / 2003 & 46.194 & 574 & 199 & 21 \\
\hline CURSO 2003 / 2004 & 47.379 & 641 & 193 & 30 \\
\hline
\end{tabular}

El objeto de estudio es una muestra de alumnos PEB de la Comunidad de Madrid en sus manifestaciones y logros. En el primer estudio (2000-01) invitamos a participar a la población PEB de dicha Comunidad respondiendo 38 alumnos, una muestra altamente representativa de la población en las condiciones de muestreo más desfavorables
( $\mathrm{p}=\mathrm{q}=0,5$ y nivel de confianza de 2s) (Jiménez, Álvarez, Aguado, Gil y Jiménez, 2001). En el segundo o 2003-04 dichos alumnos han vuelto a ser evaluados, respondiendo en este caso 31 alumnos. La tabla 2 recoge las muestras estudiadas y los instrumentos de recogida de datos empleados, mostrando el esbozo de un incipiente diseño longitudinal.

Tabla 2. Muestra e instrumentos utilizados en el estudio de los alumnos PEB

\begin{tabular}{|c|c|c|c|c|}
\hline ESTUDIO & \multicolumn{3}{|c|}{ MUESTRA } & \multirow[t]{2}{*}{ INSTRUMENTOS } \\
\hline 2000-01 & Varones & Mujeres & Total & \\
\hline $\begin{array}{l}\text { Alumnos } \\
\text { PEB }\end{array}$ & 17 & 21 & 38 & $\begin{array}{l}\text { Cuestionario ad hoc. Tests. Grupos de discusión libre de ambos } \\
\text { sexos }\end{array}$ \\
\hline $\begin{array}{l}\text { Padres de } \\
\text { alumnos } \\
\text { PEB }\end{array}$ & 21 & 28 & 49 & Cuestionario ad hoc. Grupos de discusión libre de ambos sexos \\
\hline $\begin{array}{l}\text { Profesores } \\
\text { de alum- } \\
\text { nos PEB }\end{array}$ & 8 & 6 & 14 & Cuestionario ad hoc. Grupos de discusión libre de ambos sexos \\
\hline \multicolumn{5}{|l|}{$\begin{array}{l}\text { ESTUDIO } \\
\text { 2003-04 }\end{array}$} \\
\hline $\begin{array}{l}\text { Alumnos } \\
\text { PEB }\end{array}$ & 17 & 14 & 31 & $\begin{array}{l}\text { Cuestionarios ad hoc y otros adaptados. Tests. Rendimiento } \\
\text { académico. Grupos de discusión libre sólo de chicas, sólo de } \\
\text { chicos y de ambos sexos. }\end{array}$ \\
\hline
\end{tabular}

Algunas precisiones. No se nos ha permitido conocer la dirección y datos de los alumnos $\mathrm{PEB}$, sino que desde la Consejería de Educación se les ha remitido a dichos alumnos un escrito del equipo investigador, invitándoles a colaborar en el proyecto. A través de los alumnos que aceptaron, invitamos a sus padres y profesores de bachillerato, en el segundo caso dirigiéndonos al Director del Centro. Los padres la acogieron positivamente, asistiendo ambos progenitores en varios casos. Los centros han respondido en menor medida, si bien la muestra representa la gama de responsabilidades docentes pues 
la forman un director y una secretaria de instituto, dos jefes de departamento, una jefa de estudios, dos orientadoras y siete profesores.

\subsection{Procedimiento}

En el curso académico 2000-01 recogimos datos procedentes de la consulta a padres, profesores y a los propios alumnos a través de un cuestionario ad hoc, que contiene algunas preguntas comunes para los tres grupos, y de sesiones de grupos de discusión libre en las que se les planteaban la temática de la educación del alumno PEB como hijo, como alumno y como persona sexuada. A los alumnos se les aplicaron además otras pruebas.

En el curso 2003-04 hemos recogido datos nuevos sobre los alumnos previamente estudiados a través de la aplicación de pruebas, de un protocolo sobre el rendimiento académico y de varias sesiones de discusión libre, centrándonos en dichas sesiones en el tema de la igualdad de los géneros. Los grupos han estado formados sólo por chicos, sólo por chicas y hubo una sesión mixta. En el primer estudio todas las sesiones fueron mixtas.

Las sesiones de trabajo se han realizado en las dependencias de la Universidad, citando por separado a los padres, en tres sesiones de media jornada; a los profesores, una sesión de media jornada, y a los alumnos, cuatro sesiones de jornada completa en cada estudio. El procedimiento fue similar en todos los casos. Informar de los objetivos de la investigación, de la colaboración que esperábamos, aclaración de dudas y pasábamos a trabajar. Los grupos de discusión han sido a micrófono abierto, grabados en magnetófono, anónimas las intervenciones y se acordó que todos los participantes harían una primera ronda de respuestas para, posteriormente, entrar en comentarios cruzados. Eran coordinados por los responsables del proyecto, que asistían a las mismas en su práctica totalidad por resultarles especialmente interesantes.
Como hemos señalado, nuestra hipótesis general sostiene que los alumnos más capaces apenas si son formalmente contemplados por la escuela y que dentro de ésta y de la sociedad en general, se mantienen estereotipos de género discriminatorios para la mujer y especialmente para la mujer capaz, a la que se castiga doblemente por su condición de mujer y de mujer capaz.

\subsection{Perfil general del grupo}

Para saber de quién hablamos, antes de pasar al análisis de los grupos de discusión resumimos algunas características del grupo PEB (Jiménez, Aguado, Álvarez, Gil y Jiménez, 2002; Jiménez, Álvarez, Gil, Murga y Téllez, 2004, 2005).

Son alumnos cuyas edades oscilaban entre 18 y 20 años en el momento de recoger lo primeros datos (curso 2000-2001) y predominaban las chicas (53\%); son dos (50\%) o tres hermanos (24\%), primogénitos (63\%) u ocupan el segundo lugar en la fratría (18\%). La mitad de los padres tiene 50 o menos años de edad y la mitad de las madres 48 o menos años; son familias con escasa separación o divorcio (5\%). El 44\% de los padres y el $42 \%$ de las madres tienen estudios superiores. Los alumnos se incluyen en la clase social media (55\%) y media alta (37\%); los padres se incluyen en la clase media. Son hijos de padres (95\%) y madres (65\%) que trabajan fuera del hogar, nacidos en familias acomodadas que han impulsado tempranamente su autonomía personal y su interés por la educación desde direcciones complementarias como fomentado el aprendizaje extraescolar de idiomas, la lectura, la informática y la cultura en general. Tienen dedicación plena al estudio.

La mitad ha estudiado en centros públicos; el $28 \%$ en centros privados y el $22 \%$ restante en centros públicos y privados. Se consideran alumnos normales y se han sentido queridos y respetados por profesores y compañeros. Parte de ellos ha vivido en la escuela experiencias singulares como recibir pre- 
mios, participar en campeonatos, representar al centro o participar en representaciones teatrales. Tanto en casa como en el centro se han sentido diferentes, han vivido su individualidad.

Todos estudian en la universidad, realizan el curso que les corresponde por su edad y han elegido mayoritariamente carreras duras y prestigiosas pues la mitad estudia una ingeniería superior, predominando los varones en esta opción. El alto rendimiento obtenido en bachillerato se ha mantenido moderadamente hasta el paso del ecuador de los estudios universitarios (último momento estudiado), independientemente de que procedan de centros públicos o privados, sean varones o mujeres, estudien ciencias, letras o carreras técnicas.

Obtienen buenos resultados en las pruebas de capacidad, existiendo coherencia entre los resultados de las mediciones realizadas en 2000-01 y 2003-04, respectivamente. El perfil de capacidad del grupo es de una media alta pues en la mayor parte de las pruebas se sitúa en torno al cuartil superior, como ocurre en el test de Raven y en el WAIS, dos pruebas sólidas. No obstante, dada la desviación típica habida en algunas de las pruebas, cabe señalar que hay algún alumno muy inteligente junto a algún otro que se sitúa en torno a la media y que, sin embargo, ambos han sido capaces de obtener alto rendimiento académico. El método de trabajo, la autodisciplina desarrollada y la red de expectativas, recursos y apoyos generados a lo largo de los estudios sobre todo desde la educación familiar (Jiménez Fernández, 2006), son herramientas poderosas que presumiblemente lo hacen posible. Desde la perspectiva del género, la conclusión más rotunda quizá sea que no existen diferencias significativas entre los géneros en las pruebas de capacidad y que persisten algunas en el ámbito de los intereses y los valores. La expansión de la igualdad de oportunidades junto a la determinación de la mujer por formarse, explicarían estos resultados Jiménez, Álvarez, Gil, Murga y Téllez, 2005).

\subsection{Resultados del análisis de los gru- pos de discusión: Estudio 2000-01}

En cada estudio se establecieron unos puntos de discusión distintos, en función de la situación escolar del alumno y del conocimiento anterior que teníamos del grupo. Se les ha pedido que intervengan con espontaneidad y libertad. El lenguaje utilizado ha sido coloquial y suficientemente expresivo; la situación de grupo sentados en círculo, ha facilitado las intervenciones breves y el intercambio de opiniones.

A todos los grupos o alumnos, padres y profesores se les ha pedido que describan su experiencia respecto de las cuestiones planteadas, y que sugieran cambios e iniciativas que habría que introducir para dar respuesta a las diferencias entre los estudiantes. La experiencia escolar analizada se refiere básicamente a la educación obligatoria y el bachillerato. Las cuestiones han sido:

1) ¿Atiende la escuela la diversidad de los estudiantes? ¿Cómo actúa ante grupos de alumnos diferentes?

2) ¿Qué actitud mantiene la escuela ante el alumno que destaca claramente? ¿Qué debería hacer?

3) ¿Cómo se percibe al alumno y a la alumna capaz desde la familia, la escuela y entre los propios compañeros? ¿Hay prejuicios y estereotipos de género?

\subsubsection{Perspectiva de los alumnos}

Los treinta y ocho alumnos pertenecen a otros tantos centros distintos. Planteamos la primera cuestión.

1) ¿Atiende la escuela la diversidad de los estudiantes?

Las respuestas han insistido en describir que casi la única práctica de adaptación del sistema escolar a las necesidades de los estudiantes, era la de establecer niveles a la hora de agrupar a los alumnos. No constatan que 
se apliquen tests o pruebas diagnósticas específicas, sino que se establecen niveles a partir de las calificaciones del curso anterior. Se refieren a las "clases de diversificación" como grupos destinados a los alumnos problemáticos, no siempre con menos capacidad. Dentro de las clases y grupos ordinarios, no perciben adaptaciones específicas; según algunos, la enseñanza se orienta a igualar, a nivelar a todos los estudiantes:

Las clases van a un ritmo y te acomodas tú a ese ritmo o la clase no se acomoda a ti. La profesora te podrá explicar fuera de clase, pero en clase si no lo pillas es tu problema (alumna).

En la ESO (Educación Secundaria Obligatoria) somos cobayas, hay que estar ahí, hay que aguantar hasta los dieciséis años y ya está (alumno).

Señalan que se dice que los centros públicos dan más autonomía y responsabilidad al alumno, y que los centros privados están más encima. Sea o no cierto, su experiencia escolar es positiva en ambos tipos de centro, valoran el ambiente y las relaciones personales, visión acorde con el hecho de que han logrado superarla con un expediente claramente superior a la media.

He ido a un colegio público hasta el bachillerato. Luego mis padres prefirieron uno privado que no porque tienen supuestamente más nivel se preocupan más por ti (alumna).

Si has ido sólo a un privado y no estás acostumbrado a trabajar por tu cuenta, eso no te lo puede enseñar nadie si no la sabes (alumno).

2) ¿Qué actitud mantiene la escuela ante el alumno que destaca claramente? ¿Qué debería hacer?

Ante esta cuestión apuntan que contenidos y recursos están condicionados por el examen de selectividad o prueba para el ingreso en la universidad. Centros y profesores son presionados y dirigen su esfuerzo a prepararles para superarla.

Yo le planteaba a la "profe" de "mate" que quería saber más porque me interesan las matemáticas. Me dijo: No te preocupes que con lo que sabes te va a ir muy bien (alumno).

Algunos manifiestan que la atención a la diversidad se da principalmente orientada a los estudiantes menos capaces, esfuerzo que justificaría la escasa atención prestada a los más capaces. Pero afinan más allá del tópico:

Los profesores se apoyan en los alumnos que estudian, en los que saben ¿Por qué? Porque saben que le van a responder (alumno).

Me he dado cuenta por amigos que van a un instituto que los "profes" en seguida les recomiendan ir a un "módulo" (de formación profesional), en cuanto manifiestan alguna dificultad (alumno).

Tengo amigos a los que les cuesta estudiar. Los profesores no los tienen en cuenta. También en clase estaría bien que nos pudiéramos ayudar, pero eso hay que hacerlo fuera, en casa o como sea (alumno).

Perciben en los profesores una actitud poco motivada y apuntan razones como la desvalorización social de su trabajo, y la frustración de tener que enseñar a estudiantes que en gran parte no aprenden y crean problemas.

No he tenido ningún profesor que dijese:

Esto es lo que quiero hacer todos los días (alumna).

La cuestión tercera, se ha planteado en los siguientes términos:

3) ¿Cómo os veis chicos y chicas como estudiantes? ¿Cómo os ven los profesores y en casa? ¿Hay diferencias entre chicos y chicas? 
Responden que ya no se percibe tanto la diferencia entre géneros pero reconocen que hay más chicas que eligen optativas de letras y más chicos que eligen las de ciencias ¿Por qué?

En mi carrera hay minoría de chicas (estudia ingeniería industrial). No les interesa, no quieren estudiarla. Las cosas cambian. Estas cosas se solucionan solas (alumno).

No estudiamos ejemplos de contribuciones científicas y filosóficas de las mujeres porque no han existido. Ahora ya empiezan a estudiarse (alumno).

Una diferencia parece ser la competitividad que aunque se da entre y en los dos grupos, estiman que con manifestaciones diferentes:

Yo estoy haciendo Arte, que es como muy bohemio, muy relajado, pero qué va...No puedes dejar los apuntes en la biblioteca, vuelves y no los tienes. $Y$ es mucho más probable que si se los pides (los apuntes) $a$ un chico te los deje tranquilamente $y$ una chica no (alumna).

Nosotras lo hacemos de forma más sutil (alumna).

\section{¿De guante blanco? (alumno)}

Sí, pues ellas, entre ellas se llevan muy bien. Por ejemplo, de forma general no ves a dos chicas que se lleven mal abiertamente por una cuestión de este tipo pero... (alumno).

Respecto de la actitud de los padres y sus exigencias diferentes hacia los hijos e hijas, insisten mayoritariamente en que hay padres que estiman que el hijo debe optar a carreras y trabajos con mayor nivel adquisitivo, pues es el que debe mantener a la familia. Subrayan que las opiniones de los padres dependen de su experiencia personal, ideología, edad y de las propias opciones que hicieron en su día, y quieren para los hijos lo que a ellos les ha funcionado en la vida.
Los profesores, en general, tratan igual al chico que a la chica pero sigue habiendo sutilezas propias del machismo imperante. Aunque ven que las chicas son iguales o mejores estudiantes que los chicos, no les vaticinan un porvenir profesional similar, sino inferior o más difícil.

\subsubsection{Perspectiva de los padres}

Han participado 28 madres y 21 padres y venían expectantes e internamente satisfechos de ser invitados en razón del buen trabajo de su hija o hijo. Les planteamos la primera pregunta:

1) ¿Atiende la escuela la diversidad de los estudiantes? ¿Cómo actúa ante grupos de alumnos diferentes?

Se plantea la primera cuestión y se les señala que expresen su opinión respecto de las características personales de sus hijos e hijas, si hay diferencias entre unos y otras, $y$, en este caso, cuáles son y cómo se manifiestan. La mayor parte de sus testimonios reflejan satisfacción con la personalidad y comportamiento de sus vástagos:

Mi hija es maravillosa. En los estudios no le puedo pedir más. Es maravillosa con los amigos, hermanos, con su padre (madre).

La mía es entrañable. Es autónoma en casa. Fuera de casa es muy tímida. Se lleva bien con la hermana, le da consejos, incluso algunas veces se enfada conmigo (madre).

Mi hija, que también ha sido Premio Extraordinario, es muy buena estudiante pero no consigue tan buenas notas como mi hijo (PEB) que dedica incluso menos tiempo que ella (al estudio) (madre).

Mi hijo es muy responsable, diría que excesivamente responsable. Es exigente con él mismo y con los demás, con su hermano, con su padre, con su abuela, conmigo (madre). 
En el caso de nuestra hija, estudiar ha sido un hobby para ella desde pequeña. Tiene muy buena inteligencia. Le gusta estar entre los primeros lugares. Le gusta estar la tercera de la clase, camuflarse un poco. Pasar desapercibida. Desde pequeña sabe lo que quiere (madre).

Si alguna característica diferencial se insinúa, parece tener que ver con cómo se manifiesta en chicos y chicas la capacidad o, al menos, la capacidad para el éxito escolar. Los primeros son calificados de exigentes y responsables con ellos mismos así como con los demás. Las chicas tienden a no exhibir sus capacidades, a no destacar y ser agradables a los demás. En ambos casos se valora su personalidad y seguridad; saben lo que quieren.

En relación al modelo educativo de la escuela y sus prácticas, los padres manifiestan desconocer las posibles o reales diferencias. Sólo los padres y madres que tienen la docencia como profesión, muestran conocimiento y valoración de las mismas, tanto en relación a sus hijos como a su propia experiencia profesional.

En general consideran que el profesor es el elemento definitorio del modelo educativo, el corazón de la experiencia escolar de los estudiantes. Se muestran preocupados por la falta de motivación de los profesores, su pérdida de reconocimiento social, las dimensiones del fracaso escolar y las condiciones de tensión en que, en ocasiones, tienen que desarrollar su trabajo.

2) ¿Qué actitud mantiene la escuela ante el alumno que destaca claramente? ¿Qué debería hacer?

Al opinar sobre las medidas organizativas y didácticas que el sistema escolar adopta para estimular a los alumnos más capaces, estiman que son prácticamente inexistentes:

Hay chicos inteligentes que no tienen ningún rendimiento... (Los centros) no aportan suficientes medidas para apoyar a es- tos alumnos. Bueno, no aportamos ninguna (padre).

En cuanto al modelo de enseñanza...meten en clase a los niños y sólo saben echarles asignaturas. Está la naturaleza, los museos, los teatros, el cine. Una enseñanza más dinámica, más de equipo... (madre)

El tipo de relación que las familias mantienen con el centro y el grado de conocimiento de los profesores y de la escuela, oscila desde el desconocimiento total hasta el de una madre que lo califica como dependencia. En general, consideran importante conocer al profesorado y responder a las iniciativas de los centros como reuniones o convocatorias de entrevista. Sólo uno de los padres dice tomar la iniciativa cada curso, y solicitar una entrevista con los profesores para conocerlos y aportarles información relevante sobre su hija.

Cuando se les plantea cual ha sido la clave del éxito académico de sus hijos visto desde sus responsabilidades como padres, las respuestas reinciden en una misma idea:

Estar encima de ellos...El trabajo diario...El tener hábitos de estudio (madre).

Yo creo que no sólo es fundamental, sino que es prácticamente la única razón de que al final los chicos lleguen... Creo que lo prioritario es el estudio y hay que sacarlo. Cuesta mucho decirles que no se puede hacer esto, este viaje o lo que sea porque tienen que estudiar. Al final es un esfuerzo de todos pero, sobre todo, es un esfuerzo en momentos determinados, en momentos de imponer la disciplina (padre).

Nosotros disfrutamos estando en familia. Sobre todo los domingos son para estudiar. A mi me gustaría salir, ir al cine, pero hay que estudiar. Es fundamental, porque sabes que no les vas a exigir pero que tu presencia de alguna forma dice que estás allí por ellos (padre). 
Así, la dedicación de algunos padres para lograr el éxito académico de sus hijos es máxima, lo cual es, sin duda, un elemento decisivo para conseguirlo. Sin embargo, como señalaban algunos profesores, pueden estar ejerciendo una presión de consecuencias escasamente asumidas por las familias, como satisfacción con el estudio, desarrollo de capacidades y talentos no reconocidos académicamente, opciones vocacionales limitadas, relaciones personales.

Cuando se comparan las opciones vocacionales de hijos e hijas y su actitud ante ellas, aparece una idea que marca diferencias entre las actitudes paternas y maternas:

Las madres tienden a consentir, los padres son más rígidos (padre).

Las madres parecen permitir opciones más acordes con los deseos e intereses de sus hijos aunque no respondan a un patrón ideal de elección, patrón formulado por los padres en términos de prestigio social, ingresos y opciones laborales. Dice uno de ellos:

...El problema no es que sea bailarín o que sea homosexual, el problema es el dinero. Pensar si vas a tener una salida digna o no. Si la vas a tener y vas a ser feliz, estupendo. Si vas a tener una salida indigna y luego al final, por muy feliz que te creas, no vas a ser feliz. Eso es lo que yo les explico a ellos (padre).

3) ¿Cómo se percibe al alumno y a la alumna capaz desde la familia, la escuela y entre los propios compañeros? ¿Hay prejuicios y estereotipos de género?

Finalmente, cuando opinan sobre las relaciones chicas-chicos teniendo en cuenta lo que conocen de sus hijos, de sus compañeros y amigos, los padres valoran el compañerismo reinante entre ellos. Sin embargo, cuando se aborda la cuestión de las relaciones personales, reflejan algunas dificultades manifestadas por sus hijos e hijas:
El otro día mi hijo me decía que necesitaba ligar, pero que no ligaba. Dice que no le hacen caso. Y tiene muchos amigos (padre).

Mi hija lo pasó mal porque en el colegio estaban todo el día morreándose en el pasillo y ella no podía darse un piquito con nadie. Veía que todos los demás ligaban y ella no. Y no ligaba porque es muy tímida (madre).

\subsubsection{Perspectiva de los profesores}

Es el grupo minoritario, predominaban ligeramente los profesores y sus intervenciones fueron ricas. Planteamos la primera cuestión.

1) ¿Atiende la escuela la diversidad de los estudiantes? ¿Cómo actúa ante grupos de alumnos diferentes?

Uno de los participantes replantea en voz alta la pregunta. ¿Que qué está ocurriendo en los centros escolares en relación con los alumnos más capaces? ¿Qué debería hacerse? ¿Qué iniciativas y cambios serían posibles actualmente?

Estiman que los mayores esfuerzos se concentran en mantener dentro del sistema, sea como sea, a todos los alumnos durante la etapa de la escolaridad obligatoria. En grupos de treinta o más alumnos con diferencias en capacidad, motivación, expectativas y experiencia escolar previa, es complejo adaptarse a las diferencias individuales $\mathrm{y}$ grupales. Manifiestan que la exigencia de atender a todos y adaptarse a todas las diferencias con éxito carece de sentido. Es una tarea ante la que se confiesan derrotados de antemano. No disponen de modelos alternativos. Así:

La enseñanza sigue siendo repetir y repetir, y a todos lo mismo (profesor).

2) ¿Qué actitud mantiene la escuela ante el alumno que destaca claramente? ¿Qué debería hacer? 
En el contexto escolar, el buen estudiante se define como aquel que no molesta en clase, independientemente de la capacidad. El alumno capaz también se aburre y molesta, convirtiéndose en un mal alumno para el profesor. Cada profesor es adecuado para llegar con más éxito a alumnos con determinado perfil cognitivo y motivacional, pero no a todos. Entre estos últimos se encuentran tanto alumnos muy capaces como menos capaces.

Se muestran desconcertados ante una estructura organizativa que exige agrupar juntos a todos los estudiantes, apelando a que "son iguales" en el marco de una ley que supuestamente reconoce y exige respetar su diversidad. Las alternativas que formulan pasan por modificar el tipo de agrupamiento, estableciendo niveles para diversificar a partir de ellos, pero no llegan a concretar qué criterios utilizar para agrupar por niveles ni cuales serían las formas de diversificación a desarrollar. Algunos expresan su preocupación por como detectar ajustadamente las capacidades específicas de los alumnos en el marco de un currículo y unas asignaturas concebidas de forma cerrada y estricta.

Hay capacidades que tienen que ver con las asignaturas, pero hay otras que no tienen nada que ver...En el aula sólo se desarrollan algunas capacidades que hacen brillar a las personas porque sacan muy buenas notas en matemáticas...o lo que sea, pero podría haber personas de otro país o cultura que fueran personas con una capacidad grandísima y podrías ponerles todos los tests del mundo y no las descubrirías nunca. Una persona brillante en alguna cosa (orientadora).

Se ha suscitado la cuestión del papel de los padres en la educación de los hijos más capaces y la mayoría valora fundamentalmente el papel de la familia como apoyo, refuerzo y estímulo a los estudiantes. Sin embargo, señalan la excesiva presión que algunos padres ejercen sobre los hijos para conseguir buenas notas, al margen de sus intereses y necesidades.

Un chico me decía que estaba leyendo un libro de astronomía que le interesaba mucho pero se sentía culpable... No iba a servirle para sacar mejor nota. Y estaba con complejo porque piensa "estoy desperdiciando el tiempo. En vez de sacar sobresaliente, estoy leyendo un libro de astronomía" (profesora).

Algunos chicos cuando tienen entre manos un libro o una actividad no escolar escuchan en casa: "estudia, no pierdas el tiempo" (director de centro).

Una profesora alude a algunas iniciativas de carácter marginal y minoritario que existen para los alumnos más capaces. Se trata de un programa experimental de fin de semana y valora negativamente que los padres impliquen a sus hijos en ese trabajo extra, fuera de la actividad académica diaria. Implica un sobreesfuerzo y el estudiante puede sentirse más castigado que valorado por su buena capacidad.

\section{3) ¿Hay diferencias entre chicos y chicas?}

Los profesores consideran que las alumnas más capaces suelen ser respetadas, se las admira y consulta, pero a los chicos les dan miedo. Las propias compañeras también las evitan a veces:

(Los chicos) hablan de ellas con veneración, pero con ninguna tienen una relación personal (profesor).

Lo de "a las muy listas no las quiere nadie”, sigue siendo válido para las chicas (secretaria de un instituto).

\subsection{Resultados del análisis de los gru- pos de discusión: Estudio 2003-04}

Los grupos están formados por los mismos alumnos que opinaron en 2000-01. Tienen tres años más, estudian en la Universidad, nos hemos centrado en la educación y el género y hemos trabajado con un grupo exclusivamente masculino, otro sólo femenino y 
otros grupos mixtos. Los grupos de un solo sexo han resultado más ricos; los grupos mixtos son "políticamente más correctos".

Los aspectos tratados se agrupan en tres escenarios, el universitario, el familiar y el social, planteándoles las siguientes cuestiones:

1) Cómo perciben los estudiantes los roles y estereotipos de género en el contexto de la Universidad

2) Cómo perciben los estudiantes los roles y estereotipos de género en el ámbito familiar

3) Cómo perciben los estudiantes los roles y estereotipos de género en el ámbito familiar

\subsubsection{La universidad}

Se inicia el debate pidiéndoles expresen sus preocupaciones cotidianas, aquellas que les afectan cada día porque facilitan o dificultan su inserción en las aulas y en la vida universitaria. La opinión general es que en la universidad está superada la discriminación radical por razón de género, y que a ello ha contribuido la tendencia creciente y correctora de las últimas décadas, del desequilibrio entre los géneros, tanto en el número de profesoras, como de alumnas, como en las carreras tradicionalmente masculinas. Esta corrección parece haber contribuido a desdibujar los estereotipos de género prevalentes y a potenciar una aproximación de los perfiles caracterológicos, laborales y sociales de los universitarios.

He tenido más profesores que profesoras, pero no he notado ninguna diferencia entre unos y otras, ni en método, ni en enseñanza, ni en nada (alumno).

Mi carrera es muy competitiva (estudia ingeniería de telecomunicaciones)...la gente no creo que se lo fuera a tomar peor (se refiere al logro de unas notas excelentes por parte de una mujer) (alumno).
En mi Facultad el Decano es un hombre, pero yo conozco a dos Vicerrectoras (alumno).

...siempre hay tres o cuatro que son mejores, pero pueden ser chicos, pueden ser chicas (alumno).

A medida que avanza el coloquio aparecen algunas sombras. Aunque la mayoría reconoce no apreciar diferencias entre los géneros ni en brillantez intelectual, ni en el trato por parte de los profesores, emergen recuerdos de haber protagonizado situaciones de discriminación, algunas muy sutiles.

Yo como universitario observo que al menos de cara a la galería se respeta (por igual a chicos y chicas) (alumna).

Alguna vez me han tratado con favoritismo por ser una chica (alumna).

...estábamos en el laboratorio de Físicas y (el profesor dijo) que las chicas no toquen eso no lo vayan a romper. Y...a mí, eso me llegó ¡Vamos! ¡Despreciándonos por el hecho de ser chicas! (alumna)

...comentarios del estilo, es que las chicas son más trabajadoras. Que parece que si un hombre saca una matrícula, es que es inteligente, pero si una mujer saca una matrícula, es que son trabajadoras (alumna).

\subsection{2. Ámbito familiar}

Manifiestan una percepción plural de los estereotipos de género. Señalan que en la familia, la imagen tradicional de los papeles masculinos y femeninos ha experimentado cambios notables en aspectos relacionados con las tareas del hogar y en el cuidado recíproco de los miembros de la familia.

Nosotros tenemos un plan de trabajo $y$ trabajamos todos por igual (alumna).

... se van alternando y se hacen las cosas que tocan en cada momento. Y si hay que hacer cinco cosas, no se ponen a mirar a ver qué es lo típico del hombre y qué de las mujeres (alumna) 
...se lo reparten y en el momento que hay que hacer una cosa pues se hace, pero sí que es verdad que todavía hay machismo (alumna).

Este modelo familiar que presupone la igualdad básica entre los géneros no está interiorizado por los miembros adultos. Padres y sobre todo abuelos, siguen manteniendo comportamientos desiguales, discriminatorios casi siempre para con las hijas y nietas, en la medida en que le hacen asumir las tareas convencionalmente femeninas. Algunos comentarios:

...y mi hermano se levantaba y hacía su cama. E iba mi abuela y la deshacía...iy me hacía hacerle la cama a mi hermano! (alumna).

Acabamos de comer, vamos a recoger...mi abuela se echa las manos a la cabeza...tú siéntate que tú eres hombre. Recogedla vosotras que para eso hay tres mujeres en la casa (alumna).

No sucede lo mismo con nuestras estudiantes universitarias. Estas no parecen tener la sensación de que a ellas les corresponda más que a los chicos hacer las tareas domésticas, aún en el caso de que sus familiares adultos se muestren tradicionales en su concepción de los roles de género.

...yo voy a cuidar de la salud de las personas que quiero... pero no les voy a tener todo hecho. Yo no voy a estar de chacha (alumna).

...en general, en la gente de mi entorno, yo no creo que las chicas tengan la sensación de que a ellas les corresponde más que a los chicos hacer las tareas domésticas (alumno).

Aunque a nivel formal el entorno privado del grupo admite la igualdad de derechos y obligaciones en el mantenimiento de la familia, aprecian que en la práctica, el entorno social y familiar mantiene hábitos correspondientes a una concepción tradicional de las tareas familiares, que pivota sobre los hombros femeninos:

...mi madre ha sido siempre la que nos llevaba a los médicos, de compras...- también con mi hermano- la que ha ido a las reuniones de los colegios (alumna).

Es la mujer la que educa (alumna).

...en mi casa se ha antepuesto el trabajo profesional de mi padre al de mi madre (alumna).

Yo veo que a mi padre le cuesta mucho (entrar en las responsabilidades domésticas)... al final no es un trato igualitario porque no termina de interiorizar igual que mi madre (alumno).

Los estereotipos de género de las familias del grupo PEB son mucho más tradicionales en aspectos vinculados a la moral sexual y a las conductas sociales asociadas. Algunas afirmaciones son rotundas:

...si fuera mi primo no hubiera pasado... (alumna)

\section{Hay pecados selectivos (alumna)}

Por otra parte, pervive con fuerza el prejuicio de atribuir una mayor indefensión a la mujer en estos aspectos, y se mantiene igualmente un trato discriminatorio hacia la chica, a fin de preservar su integridad física y su imagen social. Padres y madres son más estrictos y controladores con sus hijas que con sus hijos pues los "efectos colaterales" negativos se acentúan en el caso de las mujeres:

Están más preocupados por el hecho de que tú te puedes quedar embarazada (alumna).

Algunas frases significativas permiten afirmar que, en general y especialmente las alumnas, perciben una concepción del rol sexual que conserva claros retazos de la diferenciación tradicional en función del género. Como botón de muestra cabe destacar algunas intervenciones femeninas: 
...son muy tolerantes, pero cuando llega este tema, es que, mi padre... (alumna).

...como se me ocurra plantear que me voy de fin de semana... (alumna).

...los padres aceptan la sexualidad de los chicos (anticonceptivos, etc.) nunca la de las chicas (alumna).

Sin embargo, la opinión propia de los alumnos y alumnas parece claramente divergente en este aspecto respecto de la de sus familiares adultos. Queda reflejada con rotundidad en la frase:

Yo soy tan dueña de mi cuerpo y de mi sexualidad como lo es mi hermano (alumna).

Finalmente, con relación a este apartado cabe destacar que no parecen existir diferencias intragrupo en la percepción de la situación. Alumnas y alumnos coinciden en sus manifestaciones y comentarios. Reflejan, por una parte, el camino recorrido a nivel macrosocial en pro de la igualdad de género, pero, a la vez, las limitaciones aún existentes en los entornos micro.

\subsubsection{Entorno social}

En este apartado reflejamos información recogida referente a un escenario amplio que hemos denominado entorno social, con aspectos laborales, profesionales, relaciones de pareja, etc. Como primera idea cabe destacar una percepción generalizada, y aparentemente clara por parte de algunos varones del grupo, de que el "espíritu de los tiempos" prima no sólo la no discriminación por razón de género, sino, incluso, la existencia de una cierta tendencia a discriminar positivamente a la mujer:

Yo creo que hay determinados campos donde ahora mismo es privilegio ser mujer (alumno).

No se muestran claras diferencias entre las percepciones de los varones y mujeres del grupo, aunque en ocasiones parece vislum- brarse en algunos alumnos la existencia de sentimientos contradictorios:

...se está fomentando mucho, yo creo que rozando el absurdo, temas como que la mitad de una cámara tenga que ser mujer y la mitad hombre, eso me parece absolutamente absurdo (alumno).

la violencia de género aumenta por reacción, hoy el hombre se siente comido el terreno (alumna).

yo creo que sí hay algo de eso, de que a algunos hombres les intimidan las mujeres inteligentes (alumno).

En general, se reconoce sin embargo que en la cuestión de género, los planos retórico y práctico no caminan de forma armónica. En nuestra sociedad coexisten posiciones ideológicas muy distintas. Resulta frecuente la pervivencia de situaciones paradójicas en las cuales, junto a un nivel tecnológico, económico y de las comunicaciones muy avanzado, coexisten roles y estereotipos de género plenamente representativos de los modelos de organización social más tradicionales. Los comentarios siguientes ilustran esta opinión:

Existen ambientes en los cuales se mantienen los roles tradicionales de la mujer y del hombre perfectamente conservados como hace cincuenta años, las aspiraciones de hombres y mujeres, copiadas de hace cincuenta años (alumno).

Yo tengo amigos que no dejan salir a su novia si no sale con ellos. $O$ que no les dejan ponerse falda sin salir con ellos (alumna).

...es que parece increíble que estás en un pueblo a sesenta kilómetros de Madrid, que tienen televisión, tienen internet, que la gente estudia en Madrid y ocurren cosas así (alumno).

...piensan que haces deporte para ponerte buenorra..., lo hago porque me gusta un cuerpo musculado (alumna) 
Respecto a las opiniones que el propio grupo manifiesta sobre las características del sexo opuesto, parece que se mantienen los estereotipos tradicionales tal vez más de lo esperado, especialmente en lo que se refiere a la despreocupación masculina por el propio aspecto junto a la sobrevaloración del físico de la mujer, y viceversa; y a la minusvaloración y temor ante la inteligencia femenina:

Son mucho más francos que las mujeres, elementalmente francos (alumna).

Los hombres tienen un punto de animal que nosotras no tenemos (alumna).

Para ellos es mucho más importante una tía con un cuerpazo (alumna).

Las chicas somos más sutiles... si a cuchillo por detrás... envenenan” (alumna).

Piensan de otra manera, si que somos diferentes pero es lo bueno que tenemos (alumno).

Las mujeres pueden hacer cinco cosas a la vez (alumna).

Hay una gran cantidad de mujeres florero...y ríen las gracias machistas... y se maquillan antes de empezar la clase (alumna).

Con relación a los comentarios a propósito del mundo profesional y laboral, alumnos y alumnas sienten que la discriminación de género se mantiene por razones diversas. Por una parte, influyen aspectos económicos, como la prioridad de los beneficios en el caso de las empresas; por otra, cuestiones de imagen vinculadas al reconocimiento social de las profesiones. Algunos comentarios ilustran la situación:

Cuando empecé a trabajar... que podía haber una chica con un curriculo impresionante pero las chicas tienen la carga de que se pueden quedar embarazadas y eso es un problema para la empresa (alumna).
Los trabajos científicos son considerados masculinos... socialmente son más considerados (alumno).

El hecho de que una chica se meta en el mundo del hombre es como progresar para ella. Pero el hecho de que un hombre se introduzca en una guardería...ha bajado en la escala social (alumna).

Finalmente, la opinión prácticamente unánime es que la sociedad española tiene aún un largo camino por recorrer hasta que la igualdad efectiva sea una realidad plenamente lograda. Opiniones al respecto son:

Yo creo que realmente al final el problema existe, lo que pasa es que quizá no en los círculos o ambientes en los que se aplican las soluciones” (alumno).

Mi hermano abre el camino, por ser chico, por ser el primero (alumna).

En ambientes más “cultivados” por fortuna hay una presión social que hace que eso no se pueda aceptar (alumno ).

Todavía en el lenguaje quedan muchos, muchos rasgos machistas (alumna).

\section{DISCUSIÓN Y CONCLUSIONES}

Se aprecia coherencia en las respuestas dadas por los tres grupos o alumnos, padres y profesores en el primer estudio. Se manifiesta, por ejemplo, cuando los tres grupos señalan que en la escuela los más capaces simplemente están en el aula; que persisten estereotipos de género especialmente discriminantes para la chica capaz, y que la familia ejerce un importante papel en la obtención del alto rendimiento, en ocasiones presionando a los hijos para que estudien sin medir las consecuencias de una polarización excesiva en lo académico. Esta confluencia en las respuestas se manifiesta asimismo desde el análisis de las dadas en el cuestionario como hemos expuesto en otro lugar. Asimismo se aprecia coherencia en las respuestas dadas por el grupo de alumnos en ambos estudios $\mathrm{y}$ 
en instrumentos distintos o cuestionario y grupo de discusión, si bien algunos matices significativos permiten apuntar a que en el segundo periodo han madurado, y sus opiniones parecen ser más prudentes, incisivas y realistas (Jiménez, Álvarez, Gil, Murga y Téllez, 2004, 2005).

En general, del conjunto de los datos destacan dos tendencias claras. Por una parte, ha habido un gran avance hacia la igualdad y se refleja en la familia, la escuela y la sociedad pero, al mismo tiempo, persisten estereotipos y desigualdades sociales, que se dan con menos virulencia en los ambientes más intelectuales, como la escuela y la universidad; en sus propias familias donde los padres mantienen expectativas similares hacia ambos géneros; en las generaciones más jóvenes frente a la de sus abuelos y padres y, finalmente, en los ambientes más abiertos e ilustrados como la universidad frente a los más cerrados o en el medio urbano frente al rural. Ponen ejemplos.

En la escuela se refleja con contradicciones y luces propias. Los profesores son conscientes de que sistemáticamente no se atiende a los alumnos más capaces, simplemente porque otro tipo de alumnos tiene necesidades socialmente más perentorias y, además, porque no es posible ser igualmente eficaz con todos los estudiantes. La enseñanza consiste básicamente en repetir, repetir y repetir, y en tratar de mantener como sea a todos los alumnos dentro del aula. Sí perciben su valía y las sutiles diferencias que se dan hacia y entre los y las más capaces, a favor de aquellos. Por su parte, los padres apoyan con determinación el rendimiento escolar de hijos e hijas, y ponen como prioridad crear las condiciones de lo que ellos entienden puede facilitarlo, aunque signifique cerrar otras puertas.

Padres, profesores y alumnos coinciden al señalar que la capacidad cognitiva y el rendimiento escolar excelente se perciben como valores positivos en los chicos y en cierto modo también en las chicas, pero pervive con fuerza aquello de "a las muy listas no las quiere nadie”. Es decir, la mujer ha de pagar un alto precio social por ser fiel a su capacidad. Asimismo afloran algunos estereotipos diferenciados en la conducta social. Los chicos serían más nobles, simples y directos; las chicas más enrevesadas y brujas. Padres y profesores señalan que las chicas muy brillantes despiertan cierto rechazo social en compañeros y compañeras, valoración apoyada indirectamente por algunos alumnos en ambos estudios. Los chicos muy brillantes tienden a ser admirados por varones y mujeres.

En la persistencia de estereotipos y en la aparición de otros estaría influyendo el propio comportamiento femenino, pues hay chicas que se resisten a afrontar el hecho de la igualdad, ya por el peso de los estereotipos y de la presión social, ya porque deben invertir mucha energía "inútil” en el intento, ya porque temen afrontar en soledad las consecuencias, ya por estas y otras razones. Estas chicas podrían ser ejemplos que continúan reproduciendo los estereotipos tradicionales en sus relaciones de pareja; capacidad económica en ellos, belleza física en ellas, como valores diferenciales supremos. Las más capaces y las más formadas, simplemente asumen la igualdad y al menos en teoría, no cederían en lo que consideran un principio básico. Sus homólogos en capacidad y preparación comparten este principio, aunque a veces apostillan sutilmente.

Chicos y chicas se afirman en la convicción general de que las diferencias en tareas, expectativas y funciones son producto de la cultura, y que se irán reequilibrando con el paso del tiempo, si se mantienen y mejoran las medidas correctoras de la tradicional desigualdad.

Se vislumbran con nitidez el peso de ciertos estereotipos, como la dificultad que encuentran los profesores, universidad incluida, en otorgar la máxima calificación a una chi- 
ca. "El mejor debe seguir siendo un varón”, apuntaba un alumno, aunque el rendimiento femenino sea superior. Estereotipo que sigue presentando nuevas caras. El que diga la última palabra debe ser el varón; el mandatario último debe ser varón; el mejor científico debe ser varón, y si así se cree, así se percibe.

En el ámbito familiar los estudiantes reconocen la existencia de estereotipos de género muy arraigados en los adultos mayores (abuelos), que mantienen comportamientos claramente discriminatorios hacia la mujer. En las generaciones intermedias, padres y madres parecen aceptar la igualdad en el plano teórico aunque la práctica evidencia numerosas contradicciones e incoherencias, especialmente en el terreno de la sexualidad. Las jóvenes generaciones, que aparentemente han avanzado notablemente en el proceso de armonización entre pensamiento y conducta, se posicionan rotundamente por la no discriminación.

La maternidad, entendida como embarazo y alumbramiento, sigue siendo tarea femenina pero no así la crianza y educación de los hijos. Este es uno de los temas con raíces más profundas y soterradas. Hay chicos y chicas que siguen pensando que aquí sí habría diferencias debidas al sexo y no sólo debidas al género o socialización diferencial. $\mathrm{Al}$ mismo tiempo hubo comentarios "en los pasillos” aludiendo a que los hombres ya no son necesarios para procrear, sólo las mujeres, decían, lo que no refleja la realidad y sí la inquietud emergente ante las nuevas manifestaciones de los hechos esenciales.

Emerge una valoración de la persona por encima del género. Las chicas, con el asentimiento de los chicos, estiman que éticamente no tienen más obligación que estos de cuidar de los seres queridos, a los que cuidarán, pero exigiéndoles corresponsabilidad y no comparten el atribuir a la mujer el papel de "la chacha de toda la vida".
En cualquier caso, aunque en comparación con las últimas décadas se ha avanzado respecto a la igualdad de género, la experiencia de vida manifestada por nuestro grupo de estudiantes apunta al mantenimiento de reductos casi inexpugnables, tanto entre las clases culturalmente poco dotadas como entre los niveles más acomodados de la sociedad. Lo que podría significar que la discriminación por género es un eje transversal que tendría que ver básicamente con el modo de situarse cada persona ante el mundo y ante los demás seres humanos, con la forma de contemplar la propia existencia y, en última instancia, con la ideología subyacente. La socialización escolar más democrática ha llevado a borrar o mitigar tradicionales diferencias de género en capacidad y está haciendo emerger diferencias en rendimiento escolar, a favor del grupo femenino en este caso, lo que lleva a pensar que la hipótesis de la socialización diferencial de los géneros encuentra apoyo en nuestros datos, datos que confirman la hipótesis de partida de la presente colaboración.

\section{REFERENCIAS}

Alfeld, C. y Liro, J. (1999). Gender, achievement, motivation, and mental healt among adolescents in the 1990. Gifted high school students. Humanities and Social Sciences, 60 (5).

Benbow, C. (1992). Academic Achievement in Mathematics and Sciencie of Students Betwen Ages 13 and 23: Are there Differences Among Students in the Top One Percent of Mathematical Ability. Journal of Educational Psychologic. Vol. 84 (1), 5161.

CIDE/Instituto de la mujer (2001). La mujer en el sistema educativo. Madrid: Autor.

Clance, P.R. (1985). The impostor phenomenon. New Woman. 15, 40-43.

Daignault, A., Cheryl Pohlman, A.E. y McCabe, A. (1999). Educar la alta capacidad de niñas y mujeres, en J. Ellis y J. Willinsky (Eds.), Niñas, mujeres y superdotación. Madrid: Narcea, 101-106. 
Elejabeita Tavera, C. (2003). Formación Profesional, en Trayectorias personales y profesionales de mujeres con estudios tradicionalmente masculinos. Madrid: CIDE/Instituto de la Mujer. 11-154.

Flecha García, C. (1996). Las primeras universitarias en España. Madrid: Nancea.

Fox, L. H. y Zimmerman, W. Z. (1988). Las mujeres superdotadas, en Freeman, J. (Dir.) Los Niños superdotados. Aspectos psicológicos y pedagógicos. Madrid: Santillana, 246-273.

García de Cortázar, M. y García de León, M. A. (1997). Mujeres en minoría. Una investigación sociológica sobre las catedráticas de universidad en España. Opiniones y actitudes, 16, 1-67.

Henning-Stout, M. y Brown-Cheatham, M. A. (1999). School psychology in a diverse world: Considerations for practice, research and teaching, en Reynolds, C. R. y Gutkin, T. B. (Eds.) The handbook of school psychology. Nueva York: John Wiley.

Horner, M. S. (1972). Toward an undestanding of achievement related conflits and women. Journal of Social Issues, 28, 157175.

Jiménez Fernández, C. (2002). La atención a la diversidad a examen: La educación de los más capaces en el sistema escolar. Bordón. Revista de Pedagogía. Vol. 54 (2 y 3), 219239.

Jiménez Fernández, C. (2004). Educación, alta capacidad y género: Diversidad y equidad, en Jiménez Fernández, C. (Coord.) Pedagogía diferencial. Diversidad y equidad. Madrid: Pearson. Prentice Hall, 401-429.

Jiménez Fernández, C. (2006). Educación familiar y alumnos con alto rendimiento. Revista Española de Pedagogía, año LXIV, mayo-agosto, 273-299.

Jiménez Fernández, C. (Responsable); Aguado, T.; Álvarez, B.; Gil, J. A. Y Jiménez, R. (2001). Prácticas educativas y actitudes y logros del alumno desde la perspectiva del género y la alta capacidad. III Plan Nacional de Investigación científica y Desarrollo Tecnológico. Instituto de la Mujer. Proyecto bianual. Departamento de Méto- dos de Investigación y Diagnóstico en Educación. Facultad de Educación. UNED.

Jiménez Fernández, C; Aguado, T.; Álvarez, B.; Gil, J. A. Y Jiménez, R. (2002). Caracterización de los alumnos con Premio Extraordinario de Bachillerato. Bordón. Revista de Pedagogía. Vol. 54 (2 y 3), 383-398.

Jiménez, C. (Dir.); Álvarez, B.; Gil, J. A.; Murga, M. A. y Téllez, JA. (2004). Educación, alta capacidad y género: Alumnas y Alumnos con Premio Extraordinario de Bachillerato. Plan Nacional de Investigación Científica y Desarrollo Tecnológico. Ministerio de Trabajo y Asuntos Sociales. Instituto de la Mujer Departamento Métodos de Investigación y Diagnóstico en Educación. Facultad de Educación. UNED.

Jiménez, C.; Álvarez, B.; Gil, J. A.; Murga, M. A. y Téllez, J. A. (2005). Educación, capacidad y género: Alumnos con Premio Extraordinario de Bachillerato, Revista de Investigación Educativa. Vol. 23 (2),391-416. Jiménez, C. (Responsable); Álvarez, B.; Gil, J. A.; Murga, M. A. y Téllez, J. A. (2006). Educación, capacidad y género: Alumnos con Becas de Excelencia en las universidades de Madrid. Memoria final del proyecto 06/HSE/0002/ 2004. Dirección General de Universidades e Investigación. Consejería de Educación. Comunidad de Madrid. Orden 1452/2004, de 16 de abril. Departamento Métodos de Investigación y Diagnóstico en Educación. Facultad de Educación. UNED.

Jones, L. y Smart, T. (1995). Confidence and Mathematics: a gender issue? Gender and Education. Vol. 13 (2), 49-68.

Kerr, B. (1991). Developing talents in girls and young women, en Colangelo, N. y Davis, G.A., Colangelo, N. y Davis, G.A. (Eds.). Handbook of Gifted Education. Massachusetts: Allyn and Bacon, 483-497.

Kerr, B. (2000). Guiding Gifted Girls and Young Women, en Heller, K. M.; Mönks, F. J. Sternberg, R. J. y Subotnik, R. F. (Eds.). International Handbook of Giftedness and Talent. Amsterdan: Elsevier, 649-657. 
Kincheloe, J. L. y Steinberg, S. R. (1999). Repensar el multiculturalismo. Barcelona: Octaedro.

López Sáez, M. (2003). Universidad, en Trayectorias personales y profesionales de mujeres con estudios tradicionalmente masculinos. Madrid: CIDE/Instituto de la Mujer. 160-267.

Landau, E. (2003). El valor de ser superdotado. Madrid: MEC/CEIM/Comunidad de Madrid. Consejería de Educación.

Lubinski, D., Benbow, C. y Sander, Ch. (1993). Reconceptualing Gender Differences in Achievement among of the Gifted, en Heller, K.A., Mönks, F.J. y Passow, A.H. (Eds.) International Handbook of Research and Development of Giftedness and Talent. Oxford: Pergamon, 693-707.

Lubinski, D., Benbow, C. y Morelock, M. J. (2000). Gender Differences in Engineering and the Physical Sciences Among the Gifted: An Inorganic-Organic Distinction, en Heller, k. M.; Mönks, F. J. Sternberg, R. J. y Subotnik, R. F. (Eds.). International Handbook of Giftedness and Talent. Amsterdan, Elsevier, 633-648.
Martín Serrano, M. (Dir.); Algarra Paredes, A.; Mangas, L. y Fernández Cornejo, J. A. (2004) La situación profesional de la mujer en las administraciones públicas. EURODOXA. Madrid: INAP/Instituto de la Mujer.

Noble, K.D. (1987) The dilemma of gifted woman, Psychology of Women Quartely, 11, 367-378.

SERVICE PUBLIC (2005). Parité: Où en est-on?, 3, marzo. Monográfico.

Sleeter, C. E. (2003). Diversity: What do teachers needs to know, en Banks, J. A. y Banks, C. A. (Eds.) Handbook of research on multicultural education. San Francisco: CA, Jossey-Bass, 187-201.

Tilstone, C., Floria, L. y Rose, R. (2003). Promoción y desarrollo de prácticas escolares inclusivas . Madrid: EOS.

Webb, R. M.; Lubinski, D. y Benbow, C. P. (2003). Mathematically Facile Adolescents UIT Math-Sciencie Aspirations: New Perspectives on Their Educational and Vocational development, Journal of Educational Psychology. Vol. 94 (4) 785-794. 


\section{ABOUT THE AUTHORS / SOBRE LOS AUTORES}

Carmen Jiménez Fernández (mjimenez@edu.uned.es). Catedrática de Pedagogía Diferencial en el Departamento de Métodos de Investigación y Diagnóstico en Educación de la Universidad Nacional de Educación a Distancia (UNED, España). Cultiva tres principales líneas de investigación: Educación, capacidad y género; Educación, diversidad, equidad e inclusión social, y Educación vial. Directora del Posgrado Experto Universitario en Diagnóstico y Educación de los alumnos con alta capacidad, Autora de medio centenar de obras publicadas en editoriales y revistas científicas del ámbito pedagógico. (Facultad de Educación, c/ Senda del Rey ,7, 28040 Madrid).

Ma Ángeles Murga Menoyo (mmurga@edu.uned.es). Doctora en Filosofía y Letras (Sección Pedagogía) y Licenciada en Psicología. Profesora Titular y Directora del Departamento de Teoría de la Educación y Pedagogía Social de la Facultad de Educación (UNED, España). Su trayectoria investigadora incluye temas de innovación educativa, enseñanza a distancia y educación en valores. (C/ Avda. Pío XII, nº 55,3 $3^{\text {a }}$ F. 28016. Madrid. España).

Beatriz Álvarez González (balvarez@edu.uned.es). Profesora Titular de la Facultad de Educación de la UNED (España). Miembro del equipo investigador del Proyecto INTER de Educación Intercultural, acreedor del Evens Prize 2005, está especializada en temas relacionados con el tratamiento educativo de la diversidad y la educación de los biendotados. Es Profesora Honorífica de la Universidad Técnica Particular de Loja (Ecuador) por sus actividades de cooperación al desarrollo. (Facultad de Educación, c/ Senda del Rey nº 7, 28040 Madrid).

Juan Antonio Gil Pascual (jgil@edu.uned.es). Licenciado en Matemáticas y Doctor en CC. de la Educación. Profesor Titular de la Facultad de Educación de la UNED (España). Experto en estudios de opinión. Coordina el Programa de Doctorado: Metodologías para el diseño, evaluación y mejora de planes, proyectos y programas educativos. (Facultad de Educación c/ Senda del rey $\mathrm{n}^{\circ}$ 7. 28040. Madrid).

José Antonio Téllez Muñoz (jatellez@edu.uned.es). Doctor en CC. de la Educación y Premio extraordinario de Doctorado. Es profesor del Departamento de Métodos de Investigación y Diagnóstico en Educación de la Universidad Nacional de Educación a Distancia (UNED, España). (C/ Fuencarral, $n^{\circ}$ 58, $2^{\circ}$ F. 28004. Madrid. España). 


\section{ARTICLE RECORD / FICHA DEL ARTÍCULO}

\begin{tabular}{|c|c|}
\hline $\begin{array}{l}\text { Reference / } \\
\text { Referencia }\end{array}$ & $\begin{array}{l}\text { Jiménez, Carmen , Álvarez, Beatriz, Gil, Juan Antonio, Murga, María de los Ángeles, Téllez, José An- } \\
\text { tonio (2006). Educación, diversidad de los más capaces y estereotipos de género. RELIEVE, v. 12, n. } 2 . \\
\text { http://www.uv.es/RELIEVE/v12n2/RELIEVEv12n2_5.htm . Consultado en (poner fecha). }\end{array}$ \\
\hline $\begin{array}{l}\text { Title / Títu- } \\
\text { lo }\end{array}$ & $\begin{array}{l}\text { Educación, diversidad de los más capaces y estereotipos de género. [Education, diversity of the most } \\
\text { able students and gender stereotypes] }\end{array}$ \\
\hline $\begin{array}{l}\text { Authors / } \\
\text { Autores }\end{array}$ & Carmen Jiménez, Beatriz Álvarez, Juan Antonio Gil, María de los Ángeles Murga, José Antonio Téllez \\
\hline $\begin{array}{l}\text { Review / } \\
\text { Revista }\end{array}$ & Revista ELectrónica de Investigación y EValuación Educativa (RELIEVE), v. 12, n. 2 \\
\hline ISSN & $1134-4032$ \\
\hline $\begin{array}{l}\text { Publication } \\
\text { date / } \\
\text { Fecha de } \\
\text { publicación }\end{array}$ & $\begin{array}{l}2006 \text { (Reception Date: } 2006 \text { July 19; Approval Date: } 2006 \text { November 7; Publication Date: } 2006 \text { No } \\
\text { vember 9) }\end{array}$ \\
\hline
\end{tabular}

This work analyses data from two consecutive studies carried on the same sample during the academic courses: 2000-01 and 2003-04, and its objective is to know the perceptions, beliefs, attitudes and values of this sample about the situation of the more able students from the perspective of gender. The sample was chosen through the criterion of being students that have earned the Baccalaureate Extraordinary Award. These valuations were gathered by means of free discussion in small groups. In the first study we also gathered their parents' opinions, together with the ones from a group of their baccalaureate teachers. The main conclusion drawn is that school does not attend these students, but on the contrary, it keeps on repeating and repeating, and despite of the advance towards the equality of gender, stereotypes, prejudices and double discrimination attitudes towards the most able women, survive. The progress has been greater among the youngest and more cultivated population, and in the most educated and open contexts like university and cities, but even in these environments and under the "politically correct”, we still find buried redoubts of machismo.

Resumen La colaboración analiza datos de dos estudios consecutivos sobre la misma muestra realizados durante los cursos 2000-01 y 2003-04, y su objetivo es conocer las percepciones, actitudes y valores de dicha muestra sobre la situación de los alumnos y alumnas más capaces desde la perspectiva del género. La muestra ha sido elegida por haber obtenido Premio Extraordinario de Bachillerato, y se han recogido dichas valoraciones mediante la discusión libre en pequeños grupos. En el primer estudio se han recogido también las opiniones de sus padres y las de un grupo de sus profesores de bachillerato. Se concluye que la escuela no atiende a estos alumnos sino que se limita a repetir, repetir y repetir, y que pese al avance producido hacia la igualdad de los géneros, perviven estereotipos, prejuicios y actitudes que discriminan doblemente a la mujer capaz. El avance ha sido mayor entre la población más joven y más ilustrada y en los ámbitos más cultos y abiertos como la universidad y las ciudades, pero aún en ellos, persisten reductos machistas soterrados bajo lo "políticamente correcto".

Attention to the diversity; education, high ability and gender; students' stereotypes and attitudes, parents and teachers and gender; education and equality and gender; gender stereotypes in the more able

Keywords students

Descriptores Atención a la diversidad; educación, alta capacidad y género; estereotipos y actitudes de alumnos, padres y profesores y género; educación e igualdad y género; estereotipos de género en los alumnos más capaces.

Institution /

Institución

Universidad Nacional de Educación a Distancia (España)

Publication

site /

http://www.uv.es/RELIEVE

Dirección

\begin{tabular}{l|l}
\hline Language / & Spanish (Title, abstract and keywords in English ) \\
Idioma &
\end{tabular} 


\section{Revista ELectrónica de Investigación y EValuación Educativa (RELIEVE)}

\section{[ ISSN: 1134-4032 ]}

(C) Copyright, RELIEVE. Reproduction and distribution of this articles it is authorized if the content is no modified and their origin is indicated (RELIEVE Journal, volume, number and electronic address of the document).

(C) Copyright, RELIEVE. Se autoriza la reproducción y distribución de este artículo siempre que no se modifique el contenido y se indique su origen (RELIEVE, volumen, número y dirección electrónica del documento). 